\title{
Microscale Warming due to Poor Ventilation at Surface Observation Stations
}

\author{
HIROFUMI SUGAWARA \\ Department of Earth and Ocean Sciences, National Defense Academy of Japan, Yokosuka, Kanagawa, Japan \\ JUNSEI KONDO \\ Department of Geophysics, Tohoku University, Sendai, Miyagi, Japan
}

(Manuscript received 28 September 2018, in final form 24 April 2019)

\begin{abstract}
Screen-level air temperature measurements at surface observation stations are influenced by local-sitescale factors. These local influences may affect global-scale climate change studies. This study investigated the influence of surface obstacles on air temperature measurements at the screen level at climate observation stations in Japan. Screen-level air temperature was measured simultaneously at two neighboring sites $\left(<100 \mathrm{~m}\right.$ apart) that differed in terms of their openness. Daytime air temperature was $0^{\circ}-1^{\circ} \mathrm{C}$ higher at the narrower site, and theoretical analysis revealed that this warming was caused by poor ventilation. At night, poor ventilation at the narrower site caused the air temperature to be $0^{\circ}-0.2^{\circ} \mathrm{Clower}$, which was demonstrated experimentally and by theoretical analysis. The range of temperature changes due to site narrowing shown in this study is not negligible in climate change studies. Guidelines for site maintenance and metadata recoding were consequently proposed in terms of site openness.
\end{abstract}

\section{Introduction}

Screen-level air temperature, the magnitude of which can be critical in analyzing global-scale climate change, at surface observation stations is influenced by site conditions (Menne et al. 2010). The influence of changes in site conditions on the temperature record must be detected (Fall et al. 2011; Runnalls and Oke 2006; Menne et al. 2010) and adjusted (Peterson et al. 1998) during climate change analyses. To accomplish this, metadata of site conditions are used, including descriptions of topography and land use or cover around the site. The metadata are used to confirm nonclimatic discontinuities in the temperature record (Vincent et al. 2012). Metadata are also used in site classification in terms of spatial representativeness (Fall et al. 2011). Furthermore, urban heat island analyses have used metadata to identify urban and rural sites in an observation network (Peterson and Owen 2005).

However, at present, there are gaps in metadatabased analyses of temperature data. The physical processes by which the metadata-recorded factors influence temperature data have not been fully clarified.

\footnotetext{
Corresponding author: Hirofumi Sugawara, hiros@nda.ac.jp
}

Therefore, the magnitude of temperature shifts caused by changes in site conditions remains unknown. Even if the metadata revealed suspicious changes that may influence temperature measurements, it is not always possible to precisely evaluate their effects on the temperature data (Menne et al. 2010). Similarly, if any anomalies were found in temperature time series, it is not always possible to tie them to changes in site conditions. This lack of knowledge about the physical processes raises concerns about whether the present method of recording metadata is adequate for future work.

Physical processes of temperature change have been described in previous studies. The metadata should include "documentation on the geography of the site and its exposure" (WMO 2008). The underlying physical processes involved in site exposure are radiation and advection, which are described in Annex 1B of WMO (2008): "shaded from the solar radiation or protected against the night radiative cooling of the air" and "artificial surfaces may heat the air."

Surface obstacles obstruct airflow and decrease wind speed at the screen level. Decreased wind causes poor ventilation and weakens the turbulent heat exchange between the ground surface and overlying atmosphere. 
Oke (1978) highlighted poor ventilation as a cause of urban local warming.

The surface obstacles evaluated in this study were not anthropogenic heat sources, such as cars or airconditioning facilities, but natural or artificial obstacles, such as trees and fences. Urbanization increases the number of such obstacles around observation sites, and tree growth exacerbates the problem. In this paper, such changes in site condition are referred to as narrowing. Surface obstacles act as roughness elements and reduce wind speed at the screen level. In turn, this weakens the turbulent heat transfer between the sun-heated ground surface and the overlying air, which results in changes in air temperature. The decrease in turbulent heat transfer causes warming at the screen level during the daytime, because the ground surface releases heat into the air. The process is not widely recognized, and, to the best of our knowledge, no studies in urban climatology have quantitatively evaluated poor ventilation (Oke 1978).

In agricultural meteorology, it is empirically known that windbreaks on farmland influence temperature (Campi et al. 2009; Cleugh 1998), although the physical process has not been clarified. Wang and Klaassen (1995) highlighted suppressed turbulence as the reason for changes in temperature. Sugita (2018) explained changes in evaporation, not temperature, on the leeside of windbreaks based on turbulent exchange. We identified a small number of other studies with results that could be related to poor ventilation at observation sites. Fujibe (2009a) found a positive correlation between decreased wind speed and increased air temperature on a decadal scale. This suggests the influence of localscale processes around the site. Shido et al. (2015) and Wada et al. (2016) measured air temperature distribution at a meteorological observation site and an open athletic field, respectively. The two studies revealed similar results, namely, higher temperatures at narrower locations during the daytime.

This study focused on poor microscale ventilation caused by surface obstacles around surface observation sites in Japan. The model theoretically clarified how much changes can be seen in the screen-level air temperature due to change in site openness (section 2). Independently from the model, the observation showed a relationship between site openness and air temperature (sections 3 and 4). The horizontal scale in this study is a few tens of meters, considering the source area distributed in the upwind direction of the sensor (WMO 2008). The air temperature measurement is exposed to multiscale influences, from global to microscale, but the alteration of surface conditions (e.g., roughness and wetness) in the source area has a greater influence than those at the other scales.

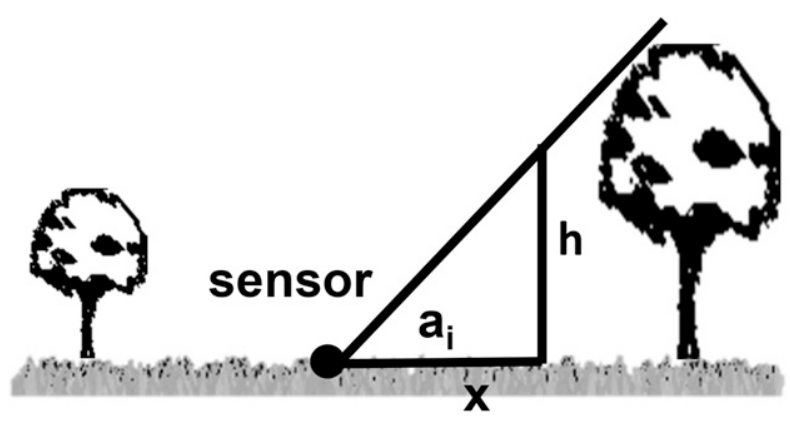

FIG. 1. Schematic illustration of site openness. The openness is defined by elevation angle $\left(a_{i}\right)$, or height $(h)$ and distance $(x)$ to obstacle.

\section{Theoretical considerations}

\section{a. Site openness}

The ventilation at an observation site is related to the site's geometrical openness. We defined site openness $\lambda$ as the aspect ratio of the volume of air above the ground (Fig. 1):

$$
\begin{aligned}
\lambda & =\left\langle\frac{x}{h}\right\rangle \\
& =\left\langle\frac{1}{\tan a_{i}}\right\rangle,
\end{aligned}
$$

where $h$ and $x$ denote the height of and distance to obstacles around the sensor, respectively. The temperature sensor is located at the origin of $x$. The brackets denote the average of the azimuth. The inverse of $\lambda$ is often used as the aspect ratio of urban street canyons. The aspect ratio is related to the flow regime in urban street canyons (Oke 1978).

\section{b. Calculation procedure}

The screen level is defined as the nearest level to the ground (generally 1-2 $\mathrm{m}$ high) in the space between surface obstacles. The screen-level temperature is influenced by many factors at multiple scales, although we focused on changes in site-local environments. The widerscale environments were assumed to be unchanged. The theoretical consideration included changes in the site's ground surface temperature, because the screen-level air temperature follows the surface temperature when any factor changes the latter. Its features should not be linear to the surface temperature change, and should be a function of atmospheric stability.

Changes in site openness influence the screen-level air temperature through changes in wind speed (ventilation). Simultaneously, site openness is related to the incoming radiation incident on the ground surface. In this section, the processes caused by site narrowing 
are described using a daytime case. Narrowing causes a reduction in wind speed at the screen level. The surface heat balance consequently changes to another equilibrium state with a higher surface temperature after the completion of narrowing. This raises the air temperature at the screen level. Moreover, the effects of the shade of surface obstacles on the ground are greater in closed sites, which lowers the air temperature.

Narrowing is further accompanied by increased longwave radiation incident on the ground, because the surface obstacles emit higher amounts of radiation in the infrared wavelength than the sky does. This increases air temperature. The following calculation deals with turbulent heat transfer, solar radiation, and longwave radiation. Note that reduced wind speed could inhibit evaporation on the ground (Sugita 2018) and could therefore change the water content of subsurface soil. However, for simplicity, we did not consider changes in soil wetness, since studying soil wetness requires long-term calculations (up to a few weeks) with a scheme for subsurface water transfer (e.g., Kondo and Saigusa 1994).

Changes in surface temperature due to turbulent heat transfer, solar radiation, and longwave radiation were calculated using a surface heat balance model. This model calculated the surface temperature using input meteorological conditions, and the screen-level air temperature was calculated from the model-calculated surface temperature using a profile function. Figure 2 illustrates the modeled situation. The narrow and open areas were adjacent to each other. The canopy-level conditions, such as air temperature, were common to both areas. However, different temperature profiles were formed for each area. The canopy- and screen-level were respectively 10 and $1.5 \mathrm{~m}$ above ground level in this calculation.

\section{c. Surface heat budget model}

The diurnal variation in surface temperature was calculated with a heat balance model similar to those of Matsushima and Kondo (1995) and Kimura and Shimizu (1994). The heat balance of the ground surface is as follows:

$$
(1-\alpha) S+\varepsilon L=H+\ell E+G+\varepsilon \sigma T_{s}^{4},
$$

where $\alpha$ is the albedo, $\varepsilon$ is the emissivity, $\sigma$ is the StefanBoltzmann constant, $S$ is the incoming solar radiation, and $L$ is the downward longwave radiation. The sensible heat flux $H$ and latent heat flux $\ell E$ are described in terms of turbulent heat transfer resistance $r$ and evaporation efficiency $\beta$ :

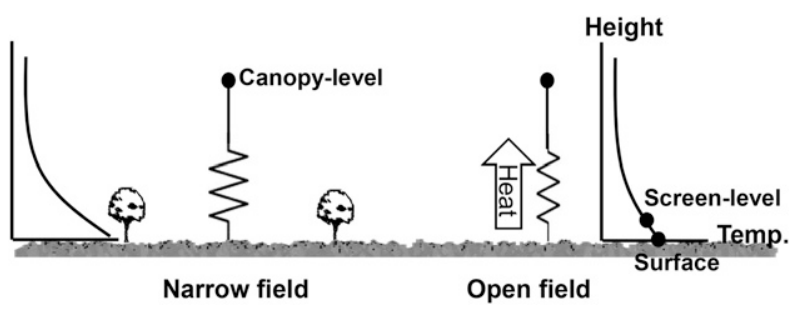

FIG. 2. Schematic illustration of the modeled situation. Narrow field shows case of $\lambda=2$. The turbulent heat flux (positive upward) is described with a resistance circuit.

$$
\begin{aligned}
& H=c_{p} \rho r^{-1}\left(T_{s}-T_{a}\right), \\
& \ell E=\ell \rho \beta r^{-1}\left[Q_{\mathrm{sat}}\left(T_{s}\right)-Q_{a}\right],
\end{aligned}
$$

where $T_{s}$ is the surface temperature; $c_{p}, \rho$, and $\ell$ are the specific heat, air density, and latent heat of vaporization, respectively; and $Q_{\text {sat }}(T)$ is the saturated specific humidity at temperature $T$. Air temperature $T_{a}$ and specific humidity $Q_{a}$ are given at the canopy level. Furthermore, $\beta$ is the ground surface wetness, with a value of $0-1$. It is often used in the study of surface heat budget (e.g., Kondo et al. 1990). The turbulent heat transfer resistance $r$ is defined between the surface and canopy level. In this study, it is given as a function of screen-level wind speed $U_{\text {screen }}$ as

$$
r^{-1}=a U_{\text {screen }}+b,
$$

where $a$ and $b$ are constants (Matsushima and Kondo 1995). Screen-level wind speed $U_{\text {screen }}$ is determined from the canopy-level wind speed $U_{\text {canopy }}$, described in section $2 \mathrm{f}$. In previous studies that used flux parameterization, such as Eq. (4), $r$ was given as a function of wind speed at the same level as the air temperature (e.g., Kondo and Watanabe 1992). However, screen-level wind speed $U_{\text {screen }}$ was used here because it more directly reflects any changes in site openness and ventilation. The subsurface ground heat flux is calculated from the vertical heat transfer equation:

$$
\frac{\partial T_{g}}{\partial t}=\frac{\lambda_{g}}{c_{g} \rho_{g}} \frac{\partial^{2} T_{g}}{\partial z^{2}},
$$

where $c_{g}, \rho_{g}$, and $\lambda_{g}$ are the specific heat, density, and heat conductance of soil, respectively, and $T_{g}$ is the subsurface temperature. Given the constant temperature at an infinitely deep level, the solution of Eq. (7) can be acquired in the form of a cyclic function (Kimura and Shimizu 1994):

$$
T_{s}=T_{s M}+\sum_{i} T_{s A i} \cos \frac{2 \pi}{\tau_{i}} t,
$$


where $T_{s M}$ and $T_{s A i}$ are the daily mean and diurnal amplitude of surface temperature, respectively, and $\tau_{i}$ is the period of the diurnal cycle. The subsurface temperature can also be written as a cyclic function, and therefore $G$ can be described as

$$
\begin{aligned}
G & =-\left.\lambda_{g} \frac{d T_{g}}{d z}\right|_{z=0}, \\
& =\sum_{i} G_{A i} \cos \left(\frac{2 \pi}{\tau_{i}} t+\frac{\pi}{4}\right),
\end{aligned}
$$

where

$$
G_{A i}=T_{s A}\left(\frac{2 \pi}{\tau_{i}}\right)^{1 / 2}\left(c_{g} \rho_{g} \lambda_{g}\right)^{1 / 2} .
$$

In our calculations, Eqs. (8) and (10) were described as the sum of the first to fourth harmonic functions in the diurnal range, that is, $\tau_{i}=24,24 / 2,24 / 3,24 / 4 \mathrm{~h}$. Substituting Eqs. (4), (5), and (10) into Eq. (3) gives an equation for $T_{s}$ (Matsushima and Kondo 1995). The input meteorological conditions are diurnal courses of $S, L, T_{a}, Q_{a}$, and $U$. The parameters $\alpha, \beta$, and $c_{g} \rho_{g} \lambda_{g}$ were assumed to be constant throughout the course of a day. Strictly speaking, $\beta$ depends on the wind speed, but this dependence is not particularly sensitive (Watanabe and Kondo 1990; Kondo and Watanabe 1992).

\section{d. Screen-level air temperature}

Based on the surface temperature calculated by the model, the screen-level air temperature was calculated using a profile function in the surface layer. The profile function was acquired by integrating the shear function $\phi_{h}$ shown by Dyer and Hicks (1970):

$$
\frac{k z}{T_{*}} \frac{\partial T}{\partial z}=\phi_{h}\left(\frac{z}{L_{o}}\right)
$$

where $L_{o}$ is the Obukhov length,

$$
L_{o}=\frac{u_{*}^{3}}{\kappa(g / T) T_{*}},
$$

where $u^{*}$ is friction velocity, determined from the screen-level wind speed and given roughness length $\left(z_{0}\right)$; $T^{*}$ is the friction temperature, acquired from the modelcalculated sensible heat flux; $\kappa$ is the Karman constant; and $g$ is the gravity acceleration. In the calculation, an iterative approach was taken for $T^{*}$ and $L_{o}$. Equation (12) failed for very narrow sites, and this point is discussed in section 5 a.

\section{e. Radiation}

Site openness influences incoming solar radiation through shade cast by surface obstacles. In the shade, direct solar radiation is obstructed, and diffused solar radiation illuminates the ground. Sites were considered to be fully sunlit or fully shaded. When more than half of a site was covered in shade, the whole area was regarded as fully shaded. Otherwise, the entire site was regarded as fully sunlit. This simplification caused a discontinuity in ground surface temperatures at relatively low sun elevation. Therefore, the modelcalculated diurnal course of temperature was analyzed at noon and at night. Note that the shaded area did not cover more than half of the site at noon even at the narrowest point. This simplification could influence the surface heat budget and, thus, the surface temperature at noon through subsurface heat storage, which depends on the diurnal history of sunlight and shade. To have avoided this simplification, it would have been necessary to consider the internal boundary layer formed above the partial shade in a site, and this was outside the scope of this study. The shadows were geometrically calculated assuming a homogeneous distribution of obstacles in the azimuth around the temperature sensor, that is, obstacles surrounding the sensor at all azimuths.

For simplicity, reflection from obstacle surfaces was not considered. Rough evaluation indicates that reflection may increase the incoming radiation incident on the ground by roughly $7 \%$, depending on the reflectance of the obstacle surface. Examples of incoming solar radiation incident on the ground surface at the sites are shown in Fig. 3. Calculations in this study assumed cloud-free conditions. Solar radiation at the canopy level was provided based on the measured values on typical clear weather days.

Incoming longwave radiation to the ground was calculated as the sum of radiation from the sky $\left(L_{\text {sky }}\right)$ and obstacles $\left(L_{\text {obstacles }}\right)$ :

$$
L=\psi L_{\text {sky }}+(1-\psi) L_{\text {obstacles }}
$$

The sky view factor $(\psi)$ is the solid-angle fraction of the sky in the overlying hemisphere (Oke 1981). The radiation from the cloud-free sky at each incident zenith angle was parameterized with air temperature and humidity (Kondo 1994). The radiation from obstacles was calculated as $\sigma T_{o}^{4}$, where the daytime and nighttime obstacle surface temperature $T_{o}$ was assumed to be $T_{m}+4^{\circ} \mathrm{C}$ and $T_{m}-5^{\circ} \mathrm{C}$, respectively, where $T_{m}$ is the daily mean canopy-level air temperature, given as model input (section $2 \mathrm{~g}$ ). 


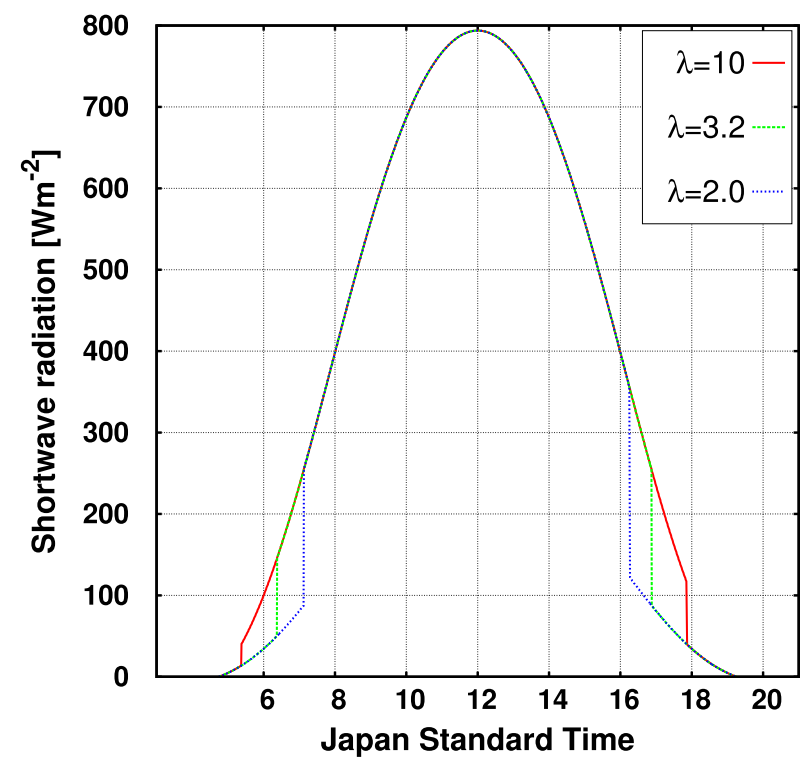

FIG. 3. Incoming shortwave radiation incident on the ground surface in May in Tokyo, Japan. Example of three different values of site openness $\lambda$. The asymmetric diurnal course occurs due to the difference between local time and Japan standard time.

\section{f. Screen-level wind speed}

The screen-level wind speed used in turbulent heat transfer resistance [Eq. (6)] should be related to site openness. The ratio of wind speed at screen and canopy level was evaluated from observations at several sites (Table 1). All sites were routine observation stations administrated by the Japan Meteorological Agency (JMA) and were equipped with aerovanes at canopy level, whose height varied depending on the site. The screen-level wind speed was measured using a $2 \mathrm{D}$ ultrasonic anemometer (Windsonic, Gill) at $1.5-2 \mathrm{~m}$ (depending on the site). Digital records at $1 \mathrm{~s}$ (screen level) and $10 \mathrm{~s}$ (canopy level) intervals were averaged for 10 -min intervals. We used data when mean wind speed was more than $3 \mathrm{~m} \mathrm{~s}^{-1}$ at canopy level.

Figure 4 shows the normalized ratio of wind speed $R_{u} / R_{u 0}$, where $R_{u}$ indicates the wind speed ratio at the observation sites:

$$
R_{u}=\frac{U_{\text {screen }}}{U_{\text {canopy }}}
$$

where $U_{\text {screen }}$ and $U_{\text {canopy }}$ are the measured screen- and canopy-level wind speeds, respectively, and $R_{u 0}$ is the ratio at an ideal (virtual) flat site with a surface cover of short lawn. It is estimated from the log-law in neutral stratification:

$$
R_{u 0}=\frac{\frac{u_{*}}{\kappa} \ln \left(\frac{z_{\text {screen }}}{z_{0}}\right)}{\frac{u_{*}}{\kappa} \ln \left(\frac{z_{\text {canopy }}-d}{z_{0}}\right)} .
$$

The surface roughness $z_{0}$ was simply set to $0.01 \mathrm{~m}$ for all sites, because precise measurement of $z_{0}$ was difficult (Grimmond et al. 1998). The displacement height $d$ was determined for each site (Table 1). The reason for using $R_{u} / R_{u 0}$ was the variable height of the upper anemometer $\left(z_{\text {canopy }}\right)$, depending on the site. Figure 4 shows the linear relationship between the log of site openness $(\log \lambda)$ and the normalized ratio $R_{u} / R_{u 0}$. This should be because the size of the eddy on the lee side of obstacles is proportional to the size of the free space at the site, which is similar to the log-shape vertical profile in the surface boundary layer (Kaimal and Finmigan 1994). The figure also shows the experimental results obtained by Ikegaya et al. (2017), who experimentally derived an equation for wind speed in the building canopy based on the data of Razak et al. (2013),

TABLE 1. List of wind observation sites. One run lasted $10 \mathrm{~min}$. Site openness $\lambda$ is the average of sector measurement using weighted wind

\begin{tabular}{|c|c|c|c|c|c|c|c|c|}
\hline Station name & Period & No. of runs & $\lambda$ & Lat $\left({ }^{\circ} \mathrm{N}\right)$ & Lon $\left({ }^{\circ} \mathrm{E}\right)$ & Terrain (slope) & Aerovane height (m) & $d(\mathrm{~m})$ \\
\hline NIAES & 2009 & 640 & 11.38 & 36.03 & 140.10 & Flat & 25.0 & 5 \\
\hline CRIED & 2009 & 826 & 9.49 & 36.11 & 140.09 & Flat & 29.5 & 5 \\
\hline Shizuoka & May-Jul 2012 & 1444 & 5.32 & 34.98 & 138.40 & Flat & 16.3 & 10 \\
\hline Kitanomaru & Jun 2012 & 1781 & 3.23 & 35.69 & 139.75 & Flat & 35.1 & 11 \\
\hline Ootemachi & Jun 2012 & 1792 & 3.35 & 35.69 & 139.76 & Flat & 35.1 & 11 \\
\hline Tateno & Jul 2011-Mar 2012 & 2145 & 8.02 & 36.06 & 140.13 & Flat & 20.4 & 5 \\
\hline Miyako & Oct-Dec 2012 & 2105 & 12.85 & 39.07 & 141.97 & Flat $\left(17^{\circ}\right)$ & 20.1 & 0 \\
\hline Nikkou & Apr-May 2013 & 1770 & 5.75 & 36.74 & 139.50 & Flat $\left(4^{\circ}\right)$ & 11.1 & 0 \\
\hline Nikkou Futarasan & Jun-Jul 2013 & 1627 & 7.22 & 36.74 & 139.50 & Flat $\left(4^{\circ}\right)$ & 11.1 & 0 \\
\hline Murotomisaki & Jan-Mar 2013 & 9964 & 10.99 & 33.25 & 134.18 & Hill $\left(21^{\circ}\right)$ & 21.8 & 11 \\
\hline Fukaura Park & Oct-Nov 2012 & 3455 & 6.78 & 40.65 & 139.93 & Hill $\left(6^{\circ}\right)$ & 21.9 & 0 \\
\hline Fukaura & Oct-Nov 2012 & 2880 & 7.20 & 40.65 & 139.93 & Hill $\left(6^{\circ}\right)$ & 2.2 & 0 \\
\hline Tsuyama Park & Dec 2012-Jan 2013 & 1914 & 16.68 & 35.06 & 134.01 & Hill $\left(18^{\circ}\right)$ & 11.7 & 0 \\
\hline Tsuyama & Jan-Mar 2013 & 2509 & 18.36 & 35.06 & 134.01 & Hill $\left(18^{\circ}\right)$ & 11.7 & 0 \\
\hline
\end{tabular}
direction frequency. Terrain slope within $500 \mathrm{~m}$ is shown. Displacement height $d$ was estimated as 0.7 times the obstacle height. 


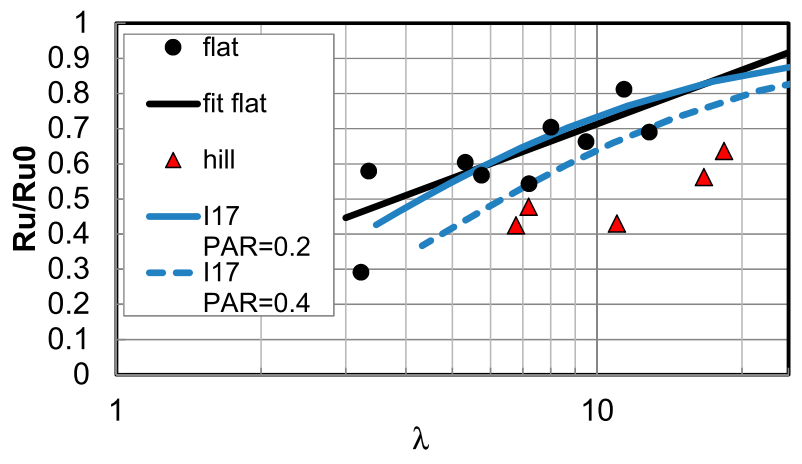

FIG. 4. Site openness $\lambda$ and normalized ratio of wind speed. I17 indicates the experimental equation by Ikegaya et al. (2017) with the plane area ratio of roofs (PAR).

Kubota et al. (2008), and Yoshie et al. (2008). The parameter in their equation was the plane area ratio of building roofs and was determined as 0.2 or 0.4 at our observation site based on aerial photographs.

Our observed results agree with those of Ikegaya et al. (2017), with two exceptions. First, the Kitanomaru site $(\lambda=3.2)$ had an $R_{u} / R_{u 0}$ value that was smaller than that of the other sites. This is due to the presence of many short trees on the lee side of tall trees and because only the tall trees determined the site openness $\lambda$. This may constitute a shortcoming of the definition of $\lambda$ in Eq. (1). Second, sites with hilly terrain, such as Fukaura, Murotomisaki, and Tsuyama, showed lower $R_{u} / R_{u 0}$ ratios (triangles in Fig. 4). The screen-level anemometer at these sites was located in the wake of the hill to the slope, following upward flow (depending on the wind direction), and the wind speed consequently decreased. A fitted equation for the flat sites is as follows:

$$
\frac{R_{u}}{R_{u 0}}=0.51 \log \left(\frac{\lambda}{0.4}\right)(3<\lambda<30) .
$$

\section{g. Calculation results}

The diurnal courses of screen-level air temperature for different site openness values were calculated using the model. The input meteorological conditions were determined considering the climatic normal for May in Tokyo, Japan, where daily total solar radiation and air temperature at the canopy level are $24.7 \mathrm{MJ} \mathrm{m}^{-2}$ and $20^{\circ} \mathrm{C}$, respectively. Relative humidity and wind speed at the canopy level were assumed to be constant throughout the day, at $60 \%$ and $3 \mathrm{~m} \mathrm{~s}^{-1}$, respectively. The parameters for the model are listed in Table 2. The heat transfer resistance was set as slightly larger at night than during the day by changing coefficients $a$ and $b$ in Eq. (6), considering the stable stratification at night. The influence of site openness was analyzed for a mean value of three hours around noon, denoted as daytime (Fig. 5), and three hours after midnight, denoted as nighttime (Fig. 6).

As the sites became narrower, air temperature increased during the daytime (Fig. 5a). The difference in air temperature between $\lambda=10$ and 2 was $1.4^{\circ} \mathrm{C}$, which is smaller than the variation in surface temperature. However, these variations in air temperature cannot be neglected in climate change studies because of their large values. The modeled physical processes of temperature change were analyzed by a sensitivity test. The change in screen-level air temperature was strongly correlated to that in surface temperature. Therefore, surface temperature was separately calculated under the influence of each influencing factor (wind speed, shortwave radiation, and longwave radiation). Figure $5 \mathrm{~b}$ shows that the temperature change was primarily caused by changes in wind speed, which is explained in the following paragraph.

As site openness decreases, screen-level wind speed decreases (Fig. 5c) as shown by Eq. (17), and therefore the thermal resistance increases. Increased resistance leads to higher surface temperature (Fig. 5b), which satisfies the surface heat balance. On the other hand, incoming shortwave radiation decreases due to the shade of obstacles, whose influence on temperature is smallest among the three influencing processes (Fig. 5b) partly because the analysis was conducted at noon. Note that the shade of the obstacles covered less than half of

TABLE 2. Parameter settings for the model.

\begin{tabular}{lcl}
\hline \hline \multicolumn{1}{c}{ Parameter } & Value & \multicolumn{1}{c}{ Reference } \\
\hline$a$ in Eq. (6) & 0.003 (day), 0.001 (night) & Sugawara and Kondo (1995) \\
$b$ in Eq. (6) & 0.009 (day), 0.001 (night) & Sugawara and Kondo (1995) \\
Albedo $\alpha$ & 0.20 & Sugawara and Kondo (1995) \\
Ground surface wetness $\beta$ & 0.38 & Kondo (1994) \\
$c_{g} \rho_{g} \lambda_{g}\left(\mathrm{~J}^{2} \mathrm{~s}^{-1} \mathrm{~K}^{-2} \mathrm{~m}^{-4}\right)$ & $10^{6}$ & Kondo (1994) \\
Surface emissivity $\varepsilon$ & 0.98 & Sugawara and Kondo (1995) \\
Ratio of solar radiation: diffuse/global & 0.31 & Kondo (1994) \\
Roughness length for momentum $z_{0}(\mathrm{~m})$ & 0.01 & Kondo and Kawanaka (1986) \\
Roughness length for heat $z_{T}(\mathrm{~m})$ & 0.02 & Kondo and Kawanaka (1986) \\
\hline
\end{tabular}



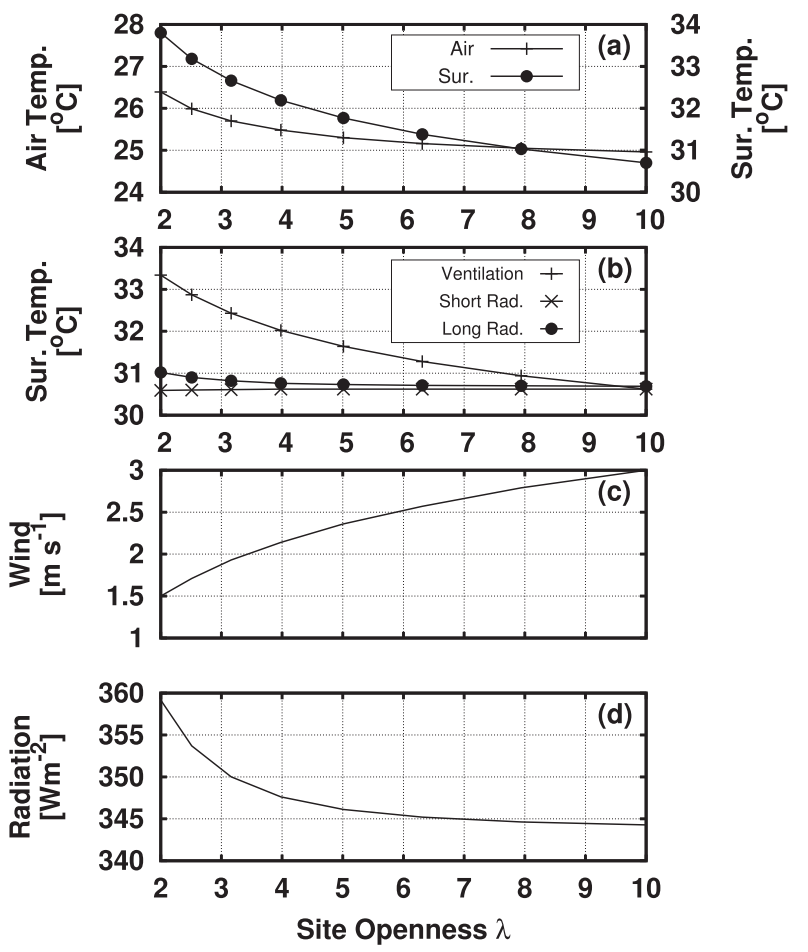

FIG. 5. Calculation results for daytime site openness variation in May. (a) Air temperature at the screen level. (b) Surface temperature of the ground. (c) Screen-level wind speed. (d) Incoming longwave radiation flux at the ground surface.

the site area at noon in this calculation condition. As the site openness decreased, the incoming longwave radiation increased (Fig. 5d), because the obstacles shared a greater portion in the sky viewed from the ground and obstacle temperature was higher than that of sky irradiance. These two radiation processes comprised vertical shielding by obstacles, and their influence was smaller than that of ventilation in the range of $\lambda$ analyzed. Consequently, the ventilation was the most significant factor.

The nighttime results (Fig. 6) showed a smaller range of variation in air temperature $\left(0.1^{\circ} \mathrm{C}\right.$ for $\left.\lambda=10-4\right)$ than the daytime results did $\left(0.5^{\circ} \mathrm{C}\right.$ for $\left.\lambda=10-4\right)$. Moreover, air temperature showed a complex trend and was at a minimum at $\lambda=4$. The downward convex shape in Fig. 6a can be explained by the sensitivity test shown in Fig. $6 \mathrm{~b}$. The test for solar radiation was included because it has some influence on nighttime temperature through subsurface heat storage. Compared to the sufficiently open site $(\lambda=10)$, incoming longwave radiation from obstacles increased at $\lambda<4$ (Fig. 6c), and this increased surface temperature (Fig. 6b). Decreased wind speed (ventilation) at $\lambda>4$, compared to $\lambda=0$, slightly reduced surface temperature (Fig. 6b). The response of nighttime surface temperature to wind speed was the

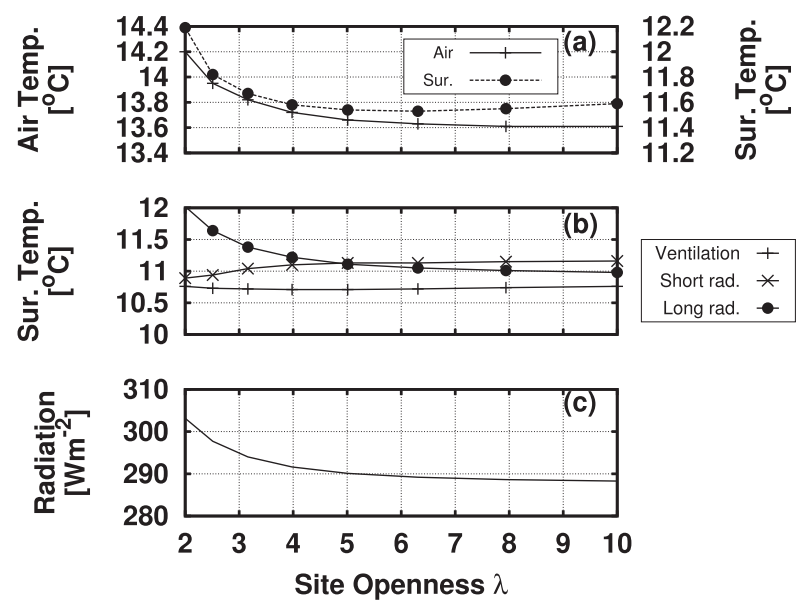

FIG. 6. Calculation results for nighttime site openness variation in May. (a) Air temperature at screen level. (b) Surface temperature of the ground. (c) Incoming longwave radiation flux at the ground surface.

opposite of that during the daytime, because the surface temperature was lower than the air temperature during the night and turbulent sensible heat was transferred from the air to the surface. The turbulenceinduced heating from the upper air mitigated surface radiative cooling.

Figures 5 and 6 illustrate the condition of fixed parameters, and we consequently considered the dependence of the parameters. If $\beta, \varepsilon$, or $c_{g} \rho_{g} \lambda_{g}$ were smaller during the daytime, higher surface temperatures would be required to achieve surface heat balance (Sugawara and Kondo 1995). Screen-level air temperature followed this trend. In this study, $\beta$ was chosen, and the dependence of air temperature difference between $\lambda=10$ and $\lambda=5$ during the daytime is shown in Fig. 7 .

The temperature difference was positive for all wetness conditions and increases as the surface dries $(\beta$ decreases), which means that narrow sites were warmer than the more open sites, especially under dry conditions. The reason for increased differences at $\beta>0.8$ is that under very wet conditions sensible heat flux becomes negative to achieve high evaporation (Kondo and Watanabe 1992). The negative sensible heat flux caused air temperature to be higher than the surface temperature through the profile function [Eq. (12)] (Fig. 7a), and increased air temperature is larger at lower wind speeds (narrower sites).

\section{Observations}

\section{a. Measurement of site openness}

Site openness $\lambda$ was measured with a theodolite, which was placed at the location of the temperature 

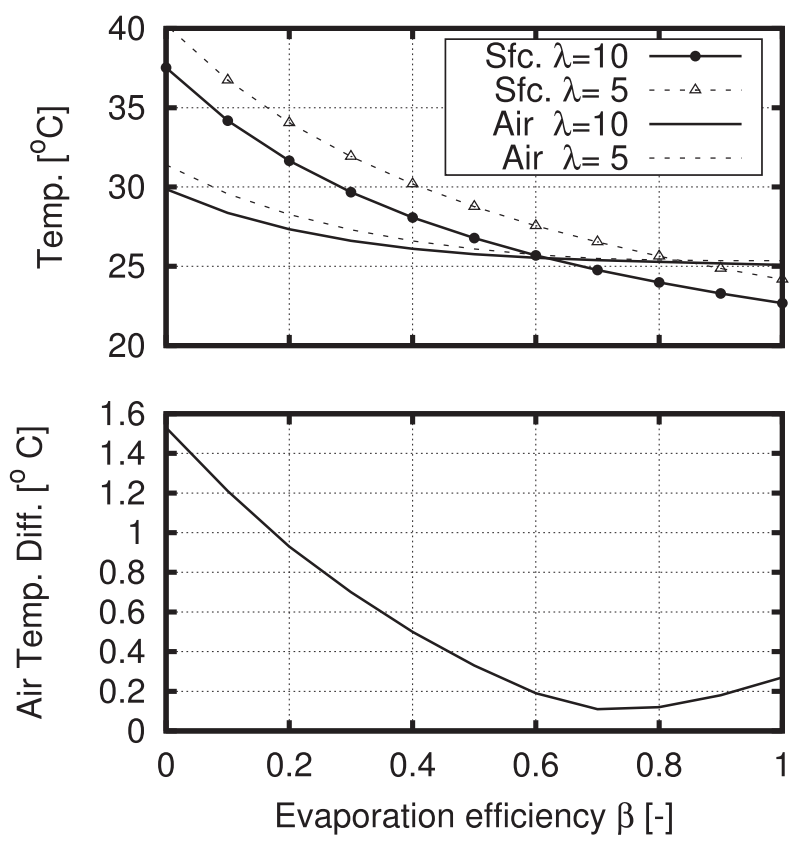

FIG. 7. Calculation results for daytime variations in wetness $\beta$. (bottom) Air temperature difference between $\lambda=10$ and $\lambda=5$.

sensor. Elevation angle of the nearest obstacles $a_{i}$ in Eq. (1) was measured at an azimuth interval of $5^{\circ}$, and $1 / \tan a_{i}$ was averaged for the whole azimuth plane. Narrow obstacles, such as flag poles, were ignored, but a wire fence was included in the measurement, because it could reduce wind speed. At the sloped site, $a_{i}$ was measured from the mean sloped surface. To achieve continuity of $\lambda$ in the very open site, $a_{i}$ was set to 1.9 for all sectors with $a_{i}<1.9$. We further attempted to use hemispherical photographs, but they exhibited large errors due to distortions at low elevation angles. Note that Wada et al. (2016) averaged $a_{i}$ for the windward sector, which was $40^{\circ}$ in width.

\section{b. Measurement of air temperature differences between narrow and open sites}

To examine the influence of openness on temperature, air temperature was measured at $1.2 \mathrm{~m}$ above ground level and compared at two adjacent points $(<100 \mathrm{~m}$ separation) with different openness values. We made several measurement runs with different site-openness pairs, as listed in Table 3. The two points were covered with short grass on the flat terrain. Figure 8 shows photographs of the measurement sites.

Site HRT was a public park bounded by a 1.8-m-high hedge. We set the open reference point at the center of the park (Fig. 8a). Other narrow points were set near the hedge (Fig. 8b), yielding several types of openness with different distances from the sensor to the hedge.
Measurements at site TMU were made by Wada et al. (2016). They took measurements with an intentionally placed curtain in an athletic field $(80 \mathrm{~m} \times 160 \mathrm{~m})$. The curtain and some trees $(6 \mathrm{~m}$ high) around the field were the obstacles. Several measurement runs with different site openness values were taken by changing the distance between the sensor and obstacles. Further details are given by Wada et al. (2016).

Site NIAES was a crop field used for agrometeorological experiments. It had some fences, a few greenhouses, and trees of around $10 \mathrm{~m}$ high. An open area in the center of the field was set as the reference point, and areas near the obstacles were selected as the narrow points. Site KMG was a routine observation site operated by the JMA and was surrounded by two- or three-story houses (7-10 m high). Site KTR was also a routine JMA observation site. It was located in a large park and surrounded by trees. An open area in the park was selected as the reference open point, and the narrow point was the field used for routine observations (Fig. 8e). Site NDA was a courtyard $(20 \mathrm{~m} \times 60 \mathrm{~m})$ surrounded by buildings ( $12 \mathrm{~m}$ high). The narrow point was set in the courtyard, and the open reference point was set in the short grass field outside the courtyard.

Measurements were taken in mainly March to October from 2012 to 2015. Light wind or calm conditions were selected on days with fair weather or partially cloudy days. These weather conditions were chosen for showing air temperature difference as shown later. The wind speed at the canopy level was $2-3 \mathrm{~m} \mathrm{~s}^{-1}$ during the daytime and $1-2 \mathrm{~m} \mathrm{~s}^{-1}$ during the nighttime on the measurement days.

\section{c. Instrumentation}

Temperature differences between the narrow and open points were in the order of $0.1^{\circ} \mathrm{C}$. The instruments were designed and manufactured specially to capture these temperature differences. The air temperature sensor was a Class A type platinum resistance thermometer of 1000 ohm (Tateyama Kagaku Kogyo Co., Ltd., STP-02), whose diameter was $2.3 \mathrm{~mm}$. A $1000 \mathrm{ohms}$ type thermometer was used rather than a $100 \mathrm{ohm}$ type to reduce the influence of junction resistance at the electric terminal. A datalogger with analog-to-digital converter (TR-55i-Pt, T\&D Co., Ltd.) was used.

The laboratory calibration showed that two sets of the same type of sensor agreed within $\pm 0.014^{\circ} \mathrm{C}$ over the temperature range $3^{\circ}-33^{\circ} \mathrm{C}$. The error range of $\pm 0.014^{\circ} \mathrm{C}$ was the relative error between the two sensor sets, and it was therefore less than the absolute error of the datalogger $\left(0.3^{\circ} \mathrm{C}\right)$. Moreover, it was lower than the resolution of the datalogger $\left(0.1^{\circ} \mathrm{C}\right)$ because it was evaluated for an average of a few hours with an interval between raw readings of $20 \mathrm{~s}(N=360-540)$. 
TABLE 3. List of temperature observation sites. One measurement run lasted 2-4 h.

\begin{tabular}{|c|c|c|c|c|c|}
\hline \multirow[b]{2}{*}{ Period } & \multicolumn{2}{|c|}{ No. of runs } & \multicolumn{2}{|c|}{ Openness $\lambda$} & \multirow[b]{2}{*}{$d \log _{10}(\lambda)$} \\
\hline & Day & Night & Open reference & Narrow & \\
\hline \multicolumn{6}{|c|}{ HRT (Hiratsuka): $35.36^{\circ} \mathrm{N}, 139.31^{\circ} \mathrm{E}$} \\
\hline 10 and 11 Apr 2013 & 2 & & 16.56 & 3.56 & -0.67 \\
\hline 12 Apr 2013 & 1 & & 16.56 & 5.98 & -0.44 \\
\hline 12 Apr 2013 & 1 & & 5.98 & 3.56 & -0.23 \\
\hline Mar and Jul 2015 & 5 & & 16.56 & 5.23 & -0.50 \\
\hline Mar and Jul 2015 & 8 & & 16.56 & 7.56 & -0.34 \\
\hline 1 Mar 2015 & 2 & & 7.56 & 5.40 & -0.15 \\
\hline Oct and Nov 2015 & 8 & & 16.70 & 4.76 & -0.55 \\
\hline 23 and 24 Oct 2015 & 2 & & 16.70 & 6.93 & -0.38 \\
\hline Oct and Nov 2015 & 8 & & 16.70 & 9.31 & -0.25 \\
\hline 9 May 2013 & & 1 & 16.56 & 3.56 & -0.67 \\
\hline 23 Mar 2015 & & 1 & 16.56 & 5.23 & -0.50 \\
\hline 24 and 25 Mar 2015 & & 2 & 16.56 & 7.56 & -0.34 \\
\hline 25 Mar 2015 & & 1 & 16.56 & 5.40 & -0.49 \\
\hline 27 and 28 Mar 2015 & & 1 & 7.56 & 5.40 & -0.15 \\
\hline Oct and Nov 2015 & & 5 & 16.70 & 4.76 & -0.55 \\
\hline 24-26 Mar 2015 & & 3 & 16.70 & 6.93 & -0.38 \\
\hline Oct and Nov 2015 & & 7 & 16.70 & 9.31 & -0.25 \\
\hline \multicolumn{6}{|c|}{ TMU (Tokyo Metropolitan University): $35.62^{\circ} \mathrm{N}, 139.38^{\circ} \mathrm{E}$} \\
\hline 22 Aug 2014 & 1 & & 14.45 & 11.23 & -0.11 \\
\hline 22 Aug 2014 & 1 & & 12.44 & 11.23 & -0.04 \\
\hline 22 Aug-18 Sep 2014 & 6 & & 12.44 & 8.91 & -0.14 \\
\hline 4 and 16 Sep 2014 & 2 & & 8.91 & 1.84 & -0.69 \\
\hline 22 Aug 2014 & 1 & & 12.44 & 1.48 & -0.92 \\
\hline 22 Aug 2014 & 1 & & 11.23 & 1.48 & -0.88 \\
\hline 22-31 Aug 2014 & 4 & & 8.91 & 1.48 & -0.78 \\
\hline 22-30 Aug 2014 & & 4 & 4.40 & 1.48 & -0.47 \\
\hline 22 Aug 2014 & & 1 & 6.65 & 1.48 & -0.65 \\
\hline 22 Aug 2014 & & 1 & 9.18 & 1.48 & -0.79 \\
\hline 22-30 Aug 2014 & & 4 & 11.54 & 1.48 & -0.89 \\
\hline 22-30 Aug 2014 & & 4 & 12.53 & 1.48 & -0.93 \\
\hline 2 and 16 Sep 2014 & & 2 & 9.18 & 1.84 & -0.70 \\
\hline 22-30 Aug 2014 & & 4 & 12.53 & 4.40 & -0.45 \\
\hline 22-30 Aug 2014 & & 4 & 12.53 & 11.54 & -0.04 \\
\hline 22-30 Aug 2014 & & 4 & 11.54 & 4.40 & -0.42 \\
\hline 22 Aug 2014 & & 1 & 11.54 & 6.65 & -0.24 \\
\hline 22 Aug 2014 & & 1 & 11.54 & 9.18 & -0.10 \\
\hline 22 Aug 2014 & & 1 & 9.18 & 6.65 & -0.14 \\
\hline \multicolumn{6}{|c|}{ NIAES (National Institute for Agro-Environmental Sciences): $36.03^{\circ} \mathrm{N}, 140.10^{\circ} \mathrm{E}$} \\
\hline 26 Oct 2012 & 1 & & 9.25 & 7.45 & -0.09 \\
\hline 1 Nov 2012 & 1 & & 9.25 & 3.83 & -0.38 \\
\hline 13 May 2013 & 1 & & 9.25 & 3.84 & -0.38 \\
\hline 14 May 2013 & 1 & & 9.25 & 1.59 & -0.76 \\
\hline \multicolumn{6}{|c|}{ KMG (Kumagaya): $36.15^{\circ} \mathrm{N}, 139.38^{\circ} \mathrm{E}$} \\
\hline Apr-Oct 2014 & 32 & & 7.20 & 6.50 & -0.04 \\
\hline Apr-Oct 2014 & 32 & & 7.20 & 5.50 & -0.12 \\
\hline 10 and 17 May 2014 & 2 & & 5.50 & 1.00 & -0.74 \\
\hline 10 and 17 May 2014 & 2 & & 5.50 & 5.30 & -0.02 \\
\hline \multicolumn{6}{|c|}{ KTR (Kitanomaru): $35.69^{\circ} \mathrm{N}, 139.75^{\circ} \mathrm{E}$} \\
\hline May-Aug 2015 & 7 & & 6.80 & 3.30 & -0.31 \\
\hline \multicolumn{6}{|c|}{ NDA (National Defense Academy) $35.26^{\circ} \mathrm{N}, 139.72^{\circ} \mathrm{E}$} \\
\hline 5 and 16 Oct 2012 & 2 & & 11.42 & 1.87 & -0.79 \\
\hline 15 Oct 2012 & & 1 & 11.42 & 1.87 & -0.79 \\
\hline
\end{tabular}




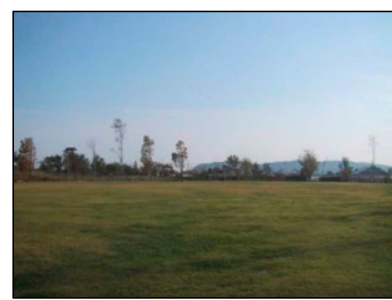

(a) $\operatorname{HRT}(\lambda=16.70)$

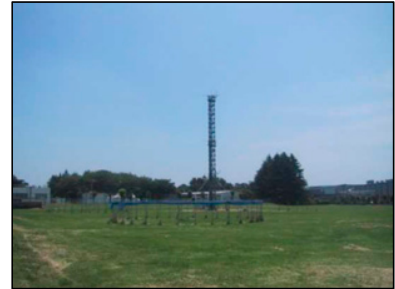

(c) NIAES $(\lambda=9.25)$

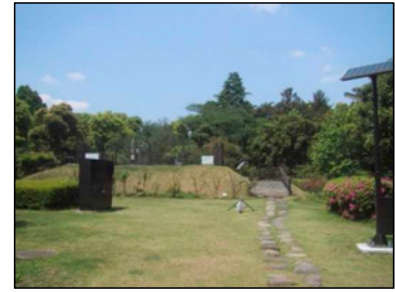

(e) $\operatorname{KTR}(\lambda=3.30)$

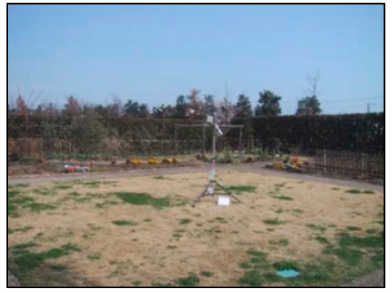

(b) HRT $(\lambda=5.23)$

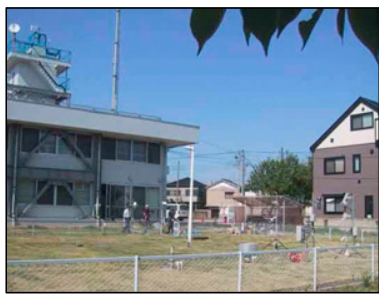

(d) KMG $(\lambda=5.50)$

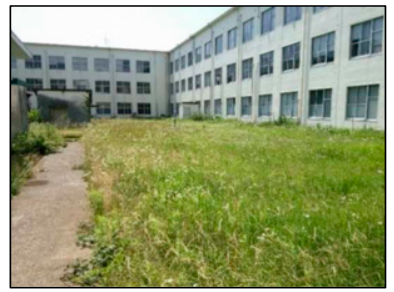

(f) $\operatorname{NDA}(\lambda=1.87)$

FIG. 8. Photographs of temperature measurement sites. See Table 3 for site name abbreviations.

The platinum resistance thermometer sensor was installed in a forced ventilation radiation shield, which was newly designed in this study. The shield had triple tubes around the sensor to avoid erroneous heating and cooling by ambient radiation. The innermost tube was painted black, which prevented the reflection of stray sunlight. The ventilation speed was $5 \mathrm{~m} \mathrm{~s}^{-1}$. Two sensor systems, namely the platinum resistance thermometer sensor, datalogger, and radiation shield, were calibrated under outdoor conditions. The two systems agreed within $\pm 0.03^{\circ} \mathrm{C}$ for an average of a few hours with an interval of $20 \mathrm{~s}$ between raw readings, indicating the total error in temperature difference at two points in this study.

Intervals of the raw reading and averaging period were determined as follows. Screen-level air temperature exhibited significant variation over time due to turbulent mixing. Therefore, we compared the temporal averages at two points in the narrow and open sites in this study, rather than comparing the instantaneous values measured. The temporal standard deviation of screen-level air temperature $\left(\sigma_{T}\right)$ was experimentally given as $0.25^{\circ} \mathrm{C}$ for the typical surface boundary layer. The time constant of our sensor was several seconds, and

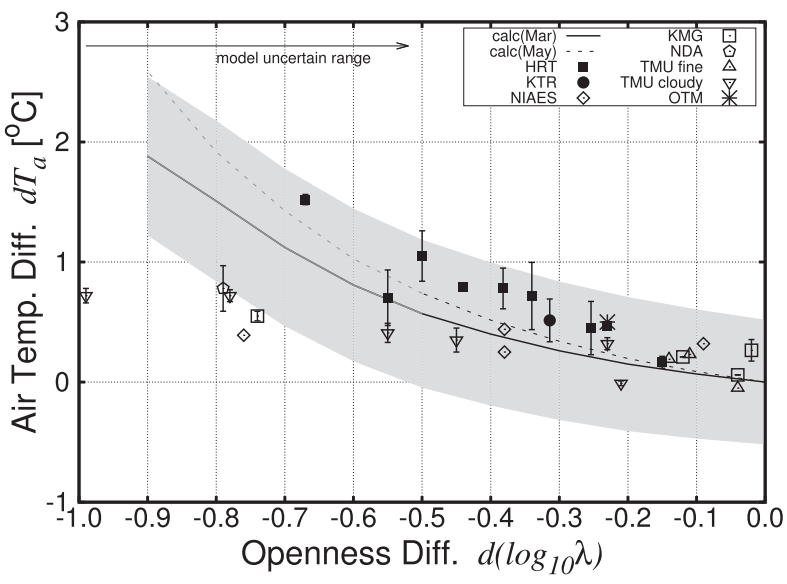

FIG. 9. Air temperature difference $d T_{a}$ at sites of differing openness. The $y$ axis is the temperature difference (narrow site minus open site). The vertical error bar indicates the standard deviation in multiple runs. See Table 3 for site name abbreviations, except OTM, which was measured by Shido et al. (2015). Note that Shido et al. (2015) showed several months' average of temperature difference. Lines show calculation result, which is temperature difference between narrow and open site $(\lambda=10)$. The gray region indicates the error range in the calculation for March owing to uncertainty of the shear function (see section 5a). For details of model uncertain area shown by an arrow, see section 5 a.

therefore the raw reading interval was set to $20 \mathrm{~s}$. The standard error $\sigma_{T} / \sqrt{ } N$ was 0.018 and $0.013^{\circ} \mathrm{C}$ for 1 and $2 \mathrm{~h}$ averages, respectively. Therefore, time periods of longer than $1 \mathrm{~h}$ are needed to derive the best performance of the sensors $\left(0.014^{\circ} \mathrm{C}\right)$, otherwise temporal variations in temperature are larger than the instrumental error. On the other hand, the average over longer periods could include diurnal variations in air temperature, and $\sigma_{T} / \sqrt{ } N$ could exceed the previous value for larger averaging periods. Therefore, we used averages of $2-5 \mathrm{~h}$ around noon and $3-5 \mathrm{~h}$ after midnight. Measurement runs with sudden changes in solar radiation due to clouds or wind direction were discarded.

\section{Observational results and comparison with calculated results}

\section{a. Daytime}

Figure 9 shows the observed results for the daytime. The $x$ axis represents the difference in openness of two sites in a common logarithm:

$$
d \log \lambda=\log \left(\lambda_{\text {narrow }}\right)-\log \left(\lambda_{\text {open }}\right),
$$

where $\lambda_{\text {open }}$ and $\lambda_{\text {narrow }}$ represent the openness in the reference open site and narrow site, respectively. An example of the corresponding street-canyon aspect 
TABLE 4. Example of geometric factors corresponding to $d \log \lambda$ at $\lambda_{\text {open }}=10$. The sky view factor was calculated for the cross point of the streets (Nakagawa 1996), which is approximately 10\% larger than that of the 2D street canyon (Oke 1981).

\begin{tabular}{lcccc}
\hline \hline$d \log \lambda$ & -0.7 & -0.5 & -0.3 & -0.1 \\
$\lambda$ & 2.0 & 3.2 & 5.0 & 7.9 \\
Canyon aspect ratio & 0.25 & 0.16 & 0.10 & 0.07 \\
Sky view factor & 0.958 & 0.982 & 0.993 & 0.996 \\
\hline
\end{tabular}

ratio and sky view factor used in urban climatology is shown in Table 4 . The aspect ratio is defined as the building height divided by the distance between the buildings.

The daytime results showed positive differences in air temperature $\left(d T_{a}\right)$, indicating that the narrower sites were warmer. The temperature difference shown in Fig. 9 was significantly larger than the measurement error $\left(0.03^{\circ} \mathrm{C}\right)$. The temperature difference increased as the difference in site openness increased (left side of figure). The field experiments showed that it was warmer in the daytime as the site narrowed. Figure 9 further shows the calculation results, which are the calculated temperature difference between narrow and open sites $(\lambda=10)$.

Two cases with different weather conditions (Table 5) were calculated with the procedure described in section $2 \mathrm{~b}$. The observations were taken mainly between March and October, and the conditions for March and May were used in the calculation. The monthly mean solar radiation was highest in May at these sites, and the other conditions used in the calculation were the same as those in section 2. The calculation results exhibited trends similar to the observations, namely, larger positive $d T_{a}$ values for larger openness differences. The observed positive $d T_{a}$ values were due to poor ventilation as described in section $2 \mathrm{~g}$. Note that the absolute value of $d T_{a}$ did not agree between the observation and the calculation because the model inputs were not specific values on observation days.

Sites HRT and KTR had larger $d T_{a}$ values than the other sites. This could be because the plants surrounding these sites emit larger amounts of sensible heat to the air compared to the other sites, which were surrounded by buildings. Buildings have a large heat capacity and therefore large heat storage and less sensible heat. Some types of evergreen plants at these site (e.g., Cinnamomum camphora and Camellia japonica) do not exhibit much evapotranspiration (Monteith 1975), and such plants could heat the air more than buildings can. The calculation revealed a tendency to overestimate $d T_{a}$ at $d \log \lambda<-0.7$ (Fig. 9). This point will be discussed later (section 5a).
TABLE 5. Weather conditions in two calculated cases (Mar and May). Daily total or averages are shown.

\begin{tabular}{lccc}
\hline \hline & $\begin{array}{c}\text { Shortwave } \\
\text { radiation }\left(\mathrm{M} \mathrm{J} \mathrm{m}^{-2}\right)\end{array}$ & $\begin{array}{c}\text { Longwave } \\
\text { radiation }\left(\mathrm{W} \mathrm{m}^{-2}\right)\end{array}$ & $\begin{array}{c}\text { Air temperature } \\
\left({ }^{\circ} \mathrm{C}\right)\end{array}$ \\
\hline Mar & 24.7 & 288 & 10 \\
May & 16.4 & 344 & 20 \\
\hline
\end{tabular}

\section{b. Nighttime}

Depending on the site, nighttime observations consisted of either negative (sites HRT and TMU) or positive (site NDA) differences in $d T_{a}$ (Fig. 10). Although site NDA had only one run, a positive $d T_{a}$ was consistent with the calculation results (Fig. 6), where the most open site $(\lambda=10)$ had the lowest air temperature. On the other hand, the negative $d T_{a}$ trend was opposite to that during the daytime. These contradictory results were evaluated using a model sensitivity test. The effect of the addition of longwave radiation (section 2e) was tested in the calculation.

Four calculation cases are shown as lines in Fig. 10. The broken and solid lines show calculations with and without the addition of radiation, respectively. The calculation with the addition of radiation considered longwave radiation from obstacles and the sky to the ground surface. The calculation without the addition of radiation considered only that from the sky, that is, the sky view factor was set to unity. Both calculations considered the influence of obstacles through wind speed and solar radiation processes. Each solid and broken line represents different weather conditions, denoted as March and May. The addition of longwave radiation made $d T_{a}$ positive, and the processes of wind speed and solar radiation made $d T_{a}$ negative. The turbulent exchange caused a negative $d T_{a}$, as discussed in section $2 \mathrm{~g}$. The calculation results explained why positive and negative $d T_{a}$ values were found in the observations. Note that the screen level was defined at $1.5 \mathrm{~m}$ in the model calculation, although air temperature was measured at $1.2 \mathrm{~m}$. The model level was followed the observation standards of the Japan Meteorological Agency, on the other hand in our observation, a different level was used due to the field administrator's regulation. A Higher level in the calculation would decrease $d T_{a}$ by $0.1^{\circ}$ and $0.3^{\circ} \mathrm{C}$ in day and night, respectively.

Variations in $d T_{a}$ according to site were due to the type of surrounding obstacles at the different sites. Site HRT was surrounded by relatively short plants $(1.5 \mathrm{~m})$, and site TMU contained a fabric curtain. Surface temperature approached air temperature at these two sites, potentially resulting in lower longwave radiation transmission to the ground surface from obstacles. 


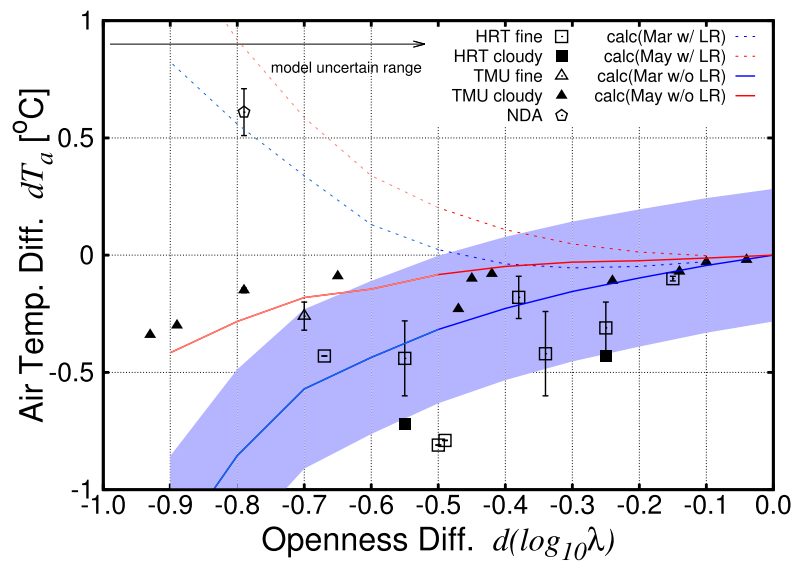

FIG. 10. As in Fig. 9, but for nighttime. Four calculation cases, representing different seasons and longwave radiation schemes, are shown by the lines. LR indicates the longwave radiation from obstacles. Observation results are divided according to the amount of cloud cover. The blue area indicates the error range in the calculation for March without longwave radiation (blue line) owing to the uncertainty of the shear function (see section $5 \mathrm{a}$ ).

At these two sites, $d T_{a}$ was influenced by turbulent heat exchange rather than longwave radiation.

The narrower point at site NDA was surrounded by buildings. Building walls are heated during the daytime and emit large amounts of longwave radiation during the nighttime (Oke 1981). The addition of longwave radiation causes a positive $d T_{a}$ (i.e., narrower point is warmer). Temperature variations at site NDA were mainly the result of the addition of longwave radiation. The openness of the narrower point at site NDA was 1.87 , which satisfies the condition of $\lambda<3$ shown as the radiation dominant situation in section $2 \mathrm{~g}$ and Fig. 6.

A comparison of sites HRT and TMU indicates that the former had a relatively larger (more negative) $d T_{a}$ at night. This tendency was similar to that in the daytime and may have been caused by the sensible heat flux from plant leaves, which cools the air during the night. Note that any differences in weather conditions in different seasons could influence the results. Measurements at site TMU were conducted in August, whereas those at site HRT were conducted during March to November.

Comparison of the observed absolute value of $d T_{a}$ during the daytime and nighttime indicates that the value during the day is larger. This indicates that $d T_{a}$ is correlated with incoming radiation incident on the ground surface. The all-wave radiation input (downward shortwave plus downward longwave, minus upward shortwave radiation) in July in Japan is roughly $1000 \mathrm{~W} \mathrm{~m}^{-2}$ during the midday and $400 \mathrm{~W} \mathrm{~m}^{-2}$ during the nighttime.

Oke (1981) measured screen-level air temperature in cities at night and showed that narrower streets were

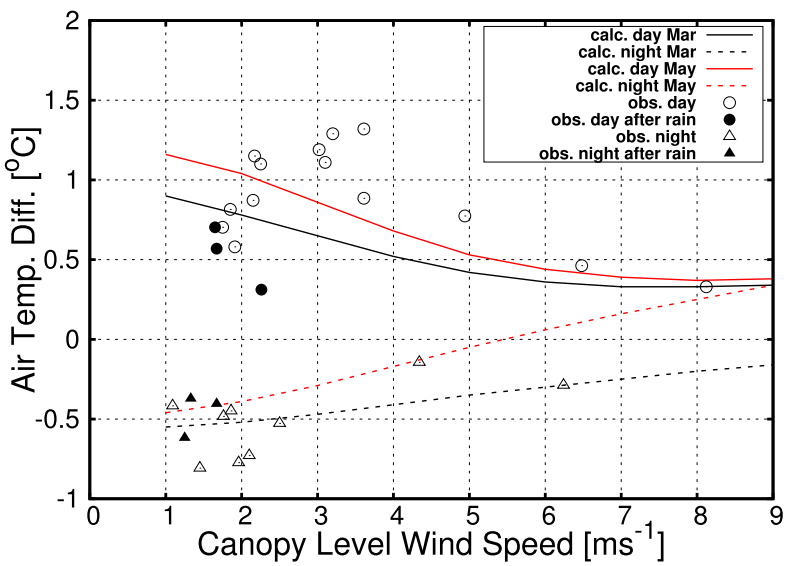

FIG. 11. Wind speed dependence on temperature difference $d T_{a}$ between open and narrow points. Observations at $d \log \lambda=-0.50$ or -0.55 for site HRT are shown.

warmer than more open ones. Calculations with the addition of radiation, shown by the broken lines in Fig. 10, indicate a similar tendency. Therefore, the temperature distribution in cities studied by Oke (1981) is influenced by longwave radiation from building walls. Oke's measurements were taken in streets with sky view factors of $0.3-0.9$. This range of site openness corresponds to $d \log \lambda=-1.5$ to -0.7 at $\lambda_{\text {open }}=10$, which exceeds the range of Fig. 10 on the narrower side of the site.

\section{c. Dependence on weather conditions}

Plots of site TMU in Fig. 9 and sites HRT and TMU in Fig. 10 were respectively divided into two types depending on the amount of cloud cover during observation. The $d T_{a}$ value did not seem to be dependent on the amount of cloud cover. However, Wada et al. (2016) noted that $d T_{a}$ was correlated with solar radiation at site TMU. Our calculation results, which indicate some difference between May and March, suggest a correlation between $d T_{a}$ and solar radiation. This could not be confirmed in Figs. 9 and 10 because only cloudless or partly cloudy days were used in the observation analysis.

The $d T_{a}$ value further depended on canopy-level wind speed. The observation runs shown in Figs. 9 and 10 were limited to calm or light-wind conditions, as noted in section $3 \mathrm{~b}$, and therefore wind speed dependence could not be confirmed from these figures. Wind speed dependence is depicted in Fig. 11, which is based on measurements at site HRT. Runs of $d \log \lambda=-0.50$ or -0.55 were used. Figure 11 shows the calculation results in four lines and observation results in four types of plots, depending on the time of day (daytime/ nighttime) and precipitation on the previous day. 
The $d T_{a}$ value approached zero as wind speed increased both in the observations and calculations. This is because the more active turbulent heat transfer under high wind speed conditions reduced solar heating of the ground surface during both daytime and nighttime radiative cooling. It was not due to increased horizontal mixing, because two measurement points were located in the canopy at all sites. The $d T_{a}$ value also seemed to depend on the surface wetness and was lower on days after rain. This could be because the latent heat from wet surfaces prevents surface heating during the daytime. At night, the larger heat capacity of wet surfaces prevented cooling.

\section{Discussion}

\section{a. Model limitations}

The model showed a tendency to overestimate $d T_{a}$ at large openness differences compared to observations (Fig. 9). This could be due to model incompleteness at the narrow sites. There could be four possible reasons. First, the extrapolation of the fitted equation in Fig. 4 could be inadequate. At the narrow sites $(\lambda<2)$, the fitted equation [Eq. (17)] underestimated $U_{\text {screen }}$, which caused an overestimation of $d T_{a}$. Relatively lower $z_{0}$ in Eq. (16) should also cause underestimation of $U_{\text {screen. }}$ Second, the (constant) coefficient for the turbulent heat transfer parameterization [Eq. (6)] could have been inadequate. The coefficients ( $a$ and $b$ ) could have depended on $\lambda$ because obstacles could produce turbulence and compensate for wind speed reductions, which was not considered in this study. Third, the partial shade condition was ignored in the calculation (section 2e). Under actual conditions, shade on the ground increases at narrower sites, which lowers the temperature.

Fourth, the profile function described in section $2 \mathrm{~d}$ may not be valid at narrow sites. The function was acquired on the assumption of constant flux in the surface boundary layer, in which the vertical eddy flux of momentum and heat is constant at any height. This assumption required horizontal homogeneity and was not always valid in narrow spaces. Surface obstacles that cause drag (surface drag and form drag) and additional heat sources disturb the constant flux layer. Obstacles that emit sensible heat disturb the constant flux assumption. In addition to anthropogenic heat sources, such as air-conditioning facilities, plants, such as hedges, also emit sensible heat to the air. Application limits in the profile function could be restricted to $\lambda<3$. The wake of an obstacle expands on the leeside to $2-3 h$, where $h$ is the height of the obstacle (Oke 1978), and the

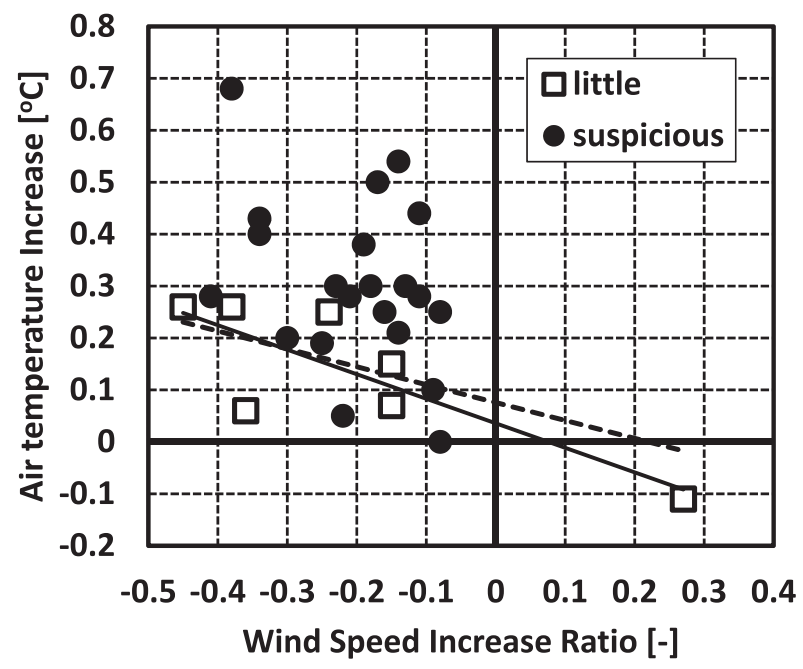

FIG. 12. Change in annual mean wind speed and temperature in historical data from Japan. The $x$ axis is the wind speed ratio $\left(U_{\text {new }}-U_{\text {old }}\right) / U_{\text {old }}$. Plots are divided into two groups of suspected and little urbanization. The lines are fitted to the plots showing little urbanization. The solid line (slope $=-0.47^{\circ} \pm 0.13^{\circ} \mathrm{C}$ ) includes one plot in the positive wind ratio, but the broken line (slope $=-0.344^{\circ} \pm 0.27^{\circ} \mathrm{C}$ ) does not. See the appendix for a full list of the sites.

flow has complex 3D features in this area. These four uncertainties could reveal that the model would be erroneous at $\lambda<3$, whose range is indicated by an arrow in Figs. 9 and 10.

In boundary layer climatology, the constant flux assumption has been validated within a $10 \%$ error (Stull 1988). Figures 9 and 10 show the range of this error in the shear function with the hatched area. The vertical scatter of observation plots was roughly the same as the vertical expansion of the hatched area, indicating that the observations satisfied the constant-flux assumption. Furthermore, the temperature change due to site openness (line curve) was larger than the hatched area, which is why the profile function was used.

\section{b. Long-term trends in temperature and wind speed}

We analyzed long-term trends in temperature and wind speed to understand how poor ventilation is expressed in climatic data. A total of 27 sites of routine observations administered by the JMA were selected based on the following conditions: 1) the site's location was not moved and 2) the site was not located in a big city. Some corrections were made to the data, and details are shown in appendix, along with the full list of sites.

Figure 12 shows the changes in annual mean temperature and wind speed over 9-48 yr for different sites. The change in wind speed ( $x$ axis) is shown in the form of a ratio, $\left(U_{\text {old }}-U_{\text {new }}\right) / U_{\text {new }}$, where $U_{\text {old }}$ and $U_{\text {new }}$ are 
the wind speeds averaged over several years at the beginning and end of the analysis period, respectively. Because even slight changes in land cover could influence temperature data, plots were divided into categories of suspected and little influence of urbanization, according to the degree of urbanization. The degree of urbanization was determined using field surveys and a land-use database (Himiyama 1995).

A larger temperature increase was observed for sites with greater decreases in wind speed (Fig. 12). Fujibe (2009a) conducted a similar analysis to that in Fig. 12, but with many more sites (408) than ours and nonetheless obtained results consistent with ours. We employed stricter selection for sites and included only a small number of sites in our analysis.

These observation sites have been under careful maintenance by the JMA, and the changes in temperature and wind are therefore due to the site ambient environment or even regional-scale climate change. In sites of suspected urbanization, wind speed reduction could have been due to increased building height around the site. On the other hand, wind speed reductions at sites that show little urbanization were caused by the growth of surrounding trees. These sites were located in a rural area and surrounded mostly by parks and forests. For example, our field survey found that in 2007 the Fukaura site was partly surrounded by naturally growing pine trees of $18 \mathrm{~m}$ high. Their height in 1970 , the beginning of analysis period, was estimated as being roughly $6 \mathrm{~m}$, assuming the typical growth rate of pine trees. There is a site (Okunikkou) where the wind speed increased, as shown in Fig. 12, and this could have been caused by the demolition of an observatory building in 1999.

The temperature increase shown in Fig. 12 may be attributed to poor ventilation at the sites, and the relationship between temperature and wind speed in Fig. 12 was compared to the results in Figs. 9 and 10. We considered changes in site openness $\lambda$ from 15 to $5(d \log \lambda=-0.477)$ because of the growth of trees surrounding the site $(3.3-10 \mathrm{~m})$ in an area with a $50 \mathrm{~m}$ radius. A change in openness of $d \log \lambda=-0.477$ caused a temperature change of $0.38^{\circ} \mathrm{C}$ in the daytime (Fig. 9) and $-0.19^{\circ} \mathrm{C}$ at night (Fig. 10). The simple average temperature during the day and night $\left(0.19^{\circ} \mathrm{C}\right)$ would be close to the daily mean value of temperature change. The change in canopy-level wind speed ( $x$ axis in Fig. 12) due to tree growth $(d(\log \lambda)=-0.477)$ was estimated as -0.38 in the log profile of wind speed above the tree canopy.

We assumed that the height of the anemometer was $18 \mathrm{~m}$, which is the average anemometer height in Table A1. We further assumed the displacement height and roughness length of the tree canopy as $0.7 h$ and $0.1 h$, respectively, based on Kondo (1971) and Brutsaert (1982), where $h$ is canopy height $(10 \mathrm{~m})$. Consequently, Figs. 9 and 10 indicate that a change in openness $(d \log \lambda=-0.477)$ caused a wind speed change of -0.38 (in its ratio) and a temperature change of $+0.19^{\circ} \mathrm{C}$ in terms of the daily mean. These values of change $\left(+0.19^{\circ} \mathrm{C} /-0.38=-0.5^{\circ} \mathrm{C}\right)$ agree roughly with the slope of the line in Fig. 12, which is fitted for plots showing little urbanization.

Therefore, long-term changes in air temperature at historical Japanese climatological observation sites (Fig. 12) could be caused by poor ventilation. Note that Fig. 12 is based on simple annual mean data, which includes cloudy days. However, Figs. 9 and 10 mainly used data for cloudless days. Temperature changes due to poor ventilation are influenced by weather conditions, as noted in section 4c. Thus, the relationship shown here needs to be further investigated in greater detail.

Fujibe (2009b) analyzed historical screen-level air temperature data in Japan and found a positive trend even in sparsely populated areas (100-300 persons $\mathrm{km}^{-2}$ ). As noted by Runnalls and Oke (2006) most common changes in landscape (e.g., irrigation) could cause nocturnal warming even if the changes do not relate to urbanization. The influence of poor ventilation on air temperature may also support this trend revealed by Fujibe (2009b). Warming could develop in a rural area where trees grew and if the measurement site became relatively narrower.

Furthermore, Fujibe (2009b) found a smaller increase of temperature in the daytime than in the nighttime and a positive trend at night. Runnalls and Oke (2006) suggested that tree growth could reduce nocturnal cooling through the alternation of the surface heat balance. These results do not indicate poor ventilation, which is accompanied by a negative (cooling) effect at night. Other processes, such as longwave radiation from obstacles, could cause warming at night, as discussed in section 4b. Moreover, broader-scale urbanization, which causes nocturnal warming, could overcome the influence of poor ventilation.

\section{c. Suggestions for site maintenance and metadata recording}

Temperature changes due to poor ventilation could affect analyses of climate change using historical temperature data. These results provide suggestions for maintenance guidelines at historical climatological observation sites. At sites that were previously sufficiently open $(\lambda=15)$, additional obstacles or tree growth reaching $2 \mathrm{~m}$ and at a horizontal distance of $10 \mathrm{~m}$ from the thermometer render the site narrow $(\lambda=5)$. 
This narrowing would cause a $\sim 0.2^{\circ} \mathrm{C}$ warming in the daily mean recorded temperature, as noted previously. The addition of obstacles that reduce wind speed at the screen level must be avoided, and trees must be trimmed regularly in and around climatological observation sites.

The WMO (2008) has guidelines for site conditions, for example, surface obstacles must be far away from the sensor to prevent it from being in the shade when the sun is higher than $5^{\circ}$. The threshold $\left(5^{\circ}\right)$ corresponds to $\lambda=$ 11 and is sufficiently open in our estimation. Our suggestion concerns any obstacles at the opposite side of the sun. Even a mesh fence, which does not cast shadows, is problematic in terms of ventilation.

The metadata of observation sites should include records of obstacles regarding their size, distance from the thermometer, and porosity, which are related to ventilation. Additional sensible heat from obstacles and trees could also change screen-level air temperature, but this was not included in our calculations. Furthermore, both plants and anthropogenic heat sources may cause serious temperature changes.

\section{Conclusions}

This study experimentally and theoretically evaluated the influence of surface obstacles on air temperature measurements at the screen level around climatological observation sites in Japan. Our experiments showed that screen-level air temperature at two neighboring sites differed by $0^{\circ}-1^{\circ} \mathrm{C}$ in the daytime. Narrower sites consistently had a higher temperature than more open sites did. This measured result was tested by theoretical analysis. The analysis calculated ground surface temperature using a surface heat budget model that considers changes in wind speed and radiation because of surface obstacles. Screen-level air temperature was calculated from the modeled surface temperature using the Monin-Obukhov similarity theory. The theoretically derived temperature trend was similar to that obtained by observations-daytime temperatures were higher in narrower sites. The analysis further showed that warming was mainly due to poor ventilation at the sites, that is, a decrease in wind speed due to surrounding obstacles.

At night, both positive and negative temperature differences at two sites were observed. The reasons for this were ascertained via the theoretical analysis. The higher temperature in the narrower site was caused by the addition of longwave radiation from the surface obstacles. The lower temperatures at narrower sites were caused by reductions in wind speed due to the presence of obstacles.
The air temperature difference $d T_{a}$ with respect to site openness was dependent on weather conditions. Larger $\left|d T_{a}\right|$ was observed under lower wind speed conditions above the canopy. However, $\left|d T_{a}\right|$ was reduced if the ground was wet. These dependencies were proven experimentally and theoretically. The theoretical analysis also showed that $d T_{a}$ increased as solar radiation increased.

The influence of poor ventilation at the sites was tested using historical data. Decadal changes in screenlevel air temperature and canopy-level wind speed were analyzed using routine observation data from Japan. The changes in temperature and wind speed were negatively correlated, in that most sites experienced decreases in wind speed and increases in temperature. The correlation quantitatively supports the influence of poor ventilation given the typical growth rate of trees around the sites. Thus, surface sites for monitoring climate change must be well maintained, which includes maintaining the site openness.

Acknowledgments. We thank the colleagues and students who assisted us in the acquisition of observations. In particular, we thank Drs. Kuwagata (NIEAS), Matsuyama (Tokyo Metropolitan University), and Naito (National Defense Academy of Japan) for their help with the observations. The observations were also supported by the JMA, Japanese Ministry of Environment. Dr. Watanabe (Hokkaido University) provided us with valuable comments for the manuscript. This study was financially supported by JSPS KAKENHI (17H02964, 17H00838, and 18K01129).

\section{APPENDIX}

\section{Correction of Wind Speed and Screen Air Temperature at Routine Observation Sites}

This section describes the procedure followed for the correction of wind speed and screen air temperature at routine observation sites (Fig. 12). Data used in Fig. 12 are shown in Table A1 with station name and analysis period. Temperature data were corrected for historical changes in number of measurements and sensor type. For wind speed, corrections were made for changes in the sensor type and measurement height. Details of these corrections are described below.

\section{a. Correction for inhomogeneous number of measurements in air temperature data}

We used historical data of daily mean air temperature produced by the JMA. In this dataset, daily mean 
TABLE A1. Changes in annual mean wind speed and screen air temperature.

\begin{tabular}{|c|c|c|c|}
\hline Station name & Period & Wind speed increase ratio & Air temperature increase $\left({ }^{\circ} \mathrm{C}\right)$ \\
\hline \multicolumn{4}{|c|}{ Little urbanization } \\
\hline Ajiro & $1973-82$ & -0.15 & 0.15 \\
\hline Yabukawa & $1988-2005$ & -0.38 & 0.26 \\
\hline Okunikkou & 1990-2000 & 0.27 & -0.11 \\
\hline Fukaura & $1970-2007$ & -0.36 & 0.06 \\
\hline Irouzaki & $1965-95$ & -0.24 & 0.25 \\
\hline Muroran & $1955-85$ & -0.15 & 0.07 \\
\hline Sumoto & 1960-2005 & -0.45 & 0.26 \\
\hline \multicolumn{4}{|c|}{ Suspected urbanization } \\
\hline Suttu & $1960-80$ & -0.08 & 0.00 \\
\hline Tsuyama & $1970-2000$ & -0.34 & 0.40 \\
\hline Tadotsu & $1965-85$ & -0.38 & 0.68 \\
\hline Fushiki & $1964-81$ & -0.18 & 0.30 \\
\hline Sakai & $1970-90$ & -0.17 & 0.50 \\
\hline Katsuura & $1955-90$ & -0.30 & 0.20 \\
\hline Okunikkou* & $1951-99$ & -0.34 & 0.43 \\
\hline Ishinomaki & $1968-83$ & -0.21 & 0.28 \\
\hline Omaesaki & $1965-90$ & -0.14 & 0.21 \\
\hline Shimizu & $1965-95$ & -0.08 & 0.25 \\
\hline Ishigaki & 1960-2003 & -0.13 & 0.30 \\
\hline Nemuro & $1965-90$ & -0.09 & 0.10 \\
\hline Abashiri & $1960-78$ & -0.23 & 0.30 \\
\hline Wakkanai & $1955-85$ & -0.41 & 0.28 \\
\hline Shionomisaki & $1965-85$ & -0.11 & 0.28 \\
\hline Iida & $1955-85$ & -0.19 & 0.38 \\
\hline Hirato & $1961-90$ & -0.25 & 0.19 \\
\hline Hamada & $1960-85$ & -0.11 & 0.44 \\
\hline Aikawa & $1960-90$ & -0.16 & 0.25 \\
\hline Uwajima & $1960-85$ & -0.22 & 0.05 \\
\hline Makurazaki & $1950-95$ & -0.14 & 0.54 \\
\hline
\end{tabular}

value was derived from different numbers of daily measurements for each period. Four types of measurement procedures have been adopted in Japan, namely, three times $(0600,1400,2200$ LST), four times $(0300$, 0900, 1500, 2100 LST), six times $(0200,0600,1000,1400$, 1800, 2200 LST), and eight times (0300, 0600, 0900, 1200, $1500,1800,2100,2400$ LST) per day. The measurements made three times per day exhibited a larger weight in the nighttime (0600 and 2200 LST) than in the daytime (1400 LST) and produced lower daily mean values than the homogeneous measurements acquired every hour. This inhomogeneity of measurement number must be corrected on a daily mean value. The correction offset was made from a virtual dataset that was thinned out from the homogeneous hourly data. The offset was made as a function of longitude, because it depends on day and night hours. The offset value was $+0.1^{\circ}$ to $+0.3^{\circ} \mathrm{C}$ for the measurements made three times per day and $-0.1^{\circ}$ to $-0.2^{\circ} \mathrm{C}$ for the measurements made four times per day. For the measurements made six and eight times per day, corrections were not made because the offset was negligible, namely, $+0.006^{\circ} \pm 0.018^{\circ} \mathrm{C}$ and $-0.002^{\circ} \pm 0.009^{\circ} \mathrm{C}$, respectively.

\section{b. Correction for sensor type in temperature measurements}

In Japan, the measurement instrument for air temperature was changed from the Assmann aspiration psychrometer with mercury thermometers in a Stevenson screen to the platinum resistance thermometer in a forced ventilation shield. The Stevenson screen was ventilated naturally without a fan. Therefore, the screen heated (cooled) in the daytime (nighttime) and caused a positive (negative) bias in temperature measurement. A correction offset was evaluated using data from

TABLE A2. Anemometer used in the routine observation by the Japan Meteorological Agency.

\begin{tabular}{lll}
\hline \hline \multicolumn{1}{c}{ Period } & \multicolumn{1}{c}{ Sensor type } & Error characteristics \\
\hline Before 1960 & Four-cup anemometer & Overvaluation \\
$1960-70$ & Three-cup & Slightly overvaluation, 1\%- \\
& anemometer & $7 \%$ (Kondo et al. 1971) \\
Dynamo mounted & Undervaluation (Okajima \\
windmill & et al. 1990) \\
After 1980 & $\begin{array}{c}\text { Pulse counter } \\
\text { mounted windmill }\end{array}$ & (Reference to previous \\
& sensors) \\
\hline
\end{tabular}


simultaneous measurements with both types of sensors. The measurements were taken by the JMA for about 40 years, since 1950, at 12 sites. The offset averaged at 12 sites for 15 years was $0.10^{\circ} \pm 0.06^{\circ} \mathrm{C}$, where the Stevenson screen type was higher. We implemented a correction of $-0.1^{\circ} \mathrm{C}$ for data from the Stevenson screen.

Andersson and Mattisson (1991) conducted similar experiments and compared the Stevenson screen and force ventilation shield. They showed that the temperature difference was less than $0.1^{\circ} \mathrm{C}$ for an average of several months. The reasons for the higher difference in our analysis can be differences in conditions between our experiments and theirs, for example, differences in wind speed or the size of the Stevenson screen. Furthermore, the aspiration speed in their experiment was $3 \mathrm{~m} \mathrm{~s}^{-1}$, which is lower than ours $\left(5 \mathrm{~m} \mathrm{~s}^{-1}\right)$.

\section{c. Correction for sensor type in wind measurements}

The type of anemometer used for routine measurements has been changed three times by the JMA. Table A2 summarizes the history with the error characteristics of each type of anemometer. Anemometer towers were often rebuilt during anemometer replacement, where the sensor type and its height were changed simultaneously. If the sensor height was increased, wind speed measured would also increase. Wind speed data after the replacement were corrected with the offset, which was identical for each replacement. The offset was determined manually considering the continuity of data around the time of the replacement and the consistency of the sensors' error characteristics.

\section{REFERENCES}

Andersson, T., and I. Mattisson, 1991: A field test of thermometer screens. WMO Instruments and Observing Methods Rep. 49, $436 \mathrm{pp}$.

Brutsaert, W., 1982: Evaporation into the Atmosphere: Theory, History, and Applications. Springer, $316 \mathrm{pp}$.

Campi, P., A. D. Palumbo, and M. Mastrorilli, 2009: Effects of tree windbreak on microclimate and wheat productivity in a Mediterranean environment. Eur. J. Agron., 30, 220-227, https://doi.org/10.1016/j.eja.2008.10.004.

Cleugh, H. A., 1998: Effect of windbreaks on air-flow, microclimate and productivity. Agrofor. Syst., 41, 55-84, https://doi.org/ 10.1023/A:1006019805109.

Dyer, J., and B. B. Hicks, 1970: Flux-gradient relationships in the constant flux layer. Quart. J. Roy. Meteor. Soc., 96, 715-721, https://doi.org/10.1002/qj.49709641012.

Fall, S., A. Watts, J. Nielsen-Gammon, E. Jones, D. Niyogi, J. R. Christy, and R. A. Pielke, 2011: Analysis of the impacts of station exposure on the U.S. Historical Climatology Network temperatures and temperature trends. J. Geophys. Res., 116, D14120, https://doi.org/10.1029/2010JD015146.

Fujibe, F., 2009a: Relation between long-term temperature and wind speed trends at surface observation stations in Japan. SOLA, 5, 81-84, https://doi.org/10.2151/sola.2009-021.
- 2009b: Detection of urban warming In recent temperature trends İn Japan. Int. J. Climatol., 29, 1811-1822, https:// doi.org/10.1002/joc. 1822 .

Grimmond, C. S. B., T. S. King, M. Roth, and T. R. Oke, 1998: Aerodynamic roughness of urban areas derived from wind observations. Bound.-Layer Meteor., 89, 1-24, https://doi.org/ 10.1023/A:1001525622213.

Himiyama, Y., 1995: Modernization and land use change. Atlas: Environmental Change in Modern Japan, O. Nishikawa, Ed., Asakura Publishing Co., 2-3.

Ikegaya, N., Y. Ikeda, A. Hagishima, A. A. Razak, and J. Tanimoto, 2017: A prediction model for wind speed ratios at pedestrian level with simplified urban canopies. Theor. Appl. Climatol., 127, 655-666, https://doi.org/ 10.1007/s00704-015-1655-z.

Kaimal, J. C., and J. Finnigan, 1994: Atmospheric Boundary Layer Flows. Oxford University Press, 289 pp.

Kimura, F., and Y. Shimizu, 1994: Estimation of sensible and latent heat fluxes from soil surface temperature using a linear air-land heat transfer model. J. Appl. Meteor., 33, 477-489, https://doi.org/10.1175/1520-0450(1994)033<0477: EOSALH $>2.0 . \mathrm{CO} ; 2$.

Kondo, J., 1971: Relationship between the roughness coefficient and other aerodynamic parameters. J. Meteor. Soc. Japan, 49, 121-124, https://doi.org/10.2151/jmsj1965.49.2_121.

, 1994: Meteorology of the Water Environment. Asakura Publishing Co., 348 pp.

, and A. Kawanaka, 1986: Numerical study on the bulk heat transfer coefficient for a variety of vegetation types and densities. Bound.-Layer Meteor., 37, 285-296, https://doi.org/ 10.1007/BF00122990.

_- , and N. Saigusa, 1994: Modelling the evaporation from bare soil with a formula for vaporization in the soil pores. J. Meteor. Soc. Japan, 72, 413-421, https://doi.org/10.2151/ jmsj1965.72.3_413.

, and T. Watanabe, 1992: Studies on the bulk transfer coefficients over a vegetated surface with a multilayer energy budget model. J. Atmos. Sci., 49, 2183-2199, https://doi.org/ 10.1175/1520-0469(1992)049<2183:SOTBTC >2.0.CO;2.

_ G. Naito, and Y. Fujinawa, 1971: Response of cup anemometer in turbulence. J. Meteor. Soc. Japan, 49, 63-74, https://doi.org/ 10.2151/jmsj1965.49.2_63.

— 1990: A Parameterization of evaporation from bare soil surfaces. J. Appl. Meteor., 29, 385-389, https://doi.org/10.1175/ 1520-0450(1990)029<0385:APOEFB > 2.0.CO;2.

Kubota, T., M. Miura, Y. Tominaga, and A. Mochida, 2008: Wind tunnel tests on the relationship between building density and pedestrian-level wind velocity: Development of guidelines for realizing acceptable wind environment in residential neighborhoods. Build. Environ., 43, 1699-1708, https://doi.org/10.1016/j.buildenv.2007.10.015.

Matsushima, D., and J. Kondo, 1995: An estimation of the bulk transfer coefficients for a bare soil surface using a linear model. J. Appl. Meteor., 34, 927-940, https://doi.org/10.1175/ 1520-0450(1995)034<0927:AEOTBT>2.0.CO;2.

Menne, M. J., C. N. Williams, and M. A. Palecki, 2010: On the reliability of the U.S. surface temperature record. J. Geophys. Res., 115, D11108, https://doi.org/10.1029/2009JD013094.

Monteith, J. L., 1975: Vegetation and the Atmosphere. Academic Press, 278 pp.

Nakagawa, K., 1996: A numerical experiment on the dependence of the surface albedo on the surface structure of an urban 
area. Geogr. Rev. Ser. A, 69, 415-435, https://doi.org/10.4157/ grj1984a.69.6_415.

Okajima, A., G. Naito, T. Fujitani, T. Mizota, Y. Iwasa, N. Chino, and T. Itoh, 1990: Wind-measuring instruments and systems. Wind Eng., 1990, 58-108, https://doi.org/10.5359/jawe.1990.58.

Oke, T. R., 1978: Boundary Layer Climate. Methuen \& Co., 372 pp.

_ 1981: Canyon geometry and the nocturnal urban heat island: Comparison of scale model and field observations. J. Climatol., 1, 237-254, https://doi.org/10.1002/joc.3370010304.

Peterson, T. C., and Coauthors, 1998: Homogeneity adjustments of in situ atmospheric climate data: A review. Int. J. Climatol., 18, 1493-1517, https://doi.org/10.1002/(SICI)1097-0088(19981115) 18:13<1493::AID-JOC329>3.0.CO;2-T.

— are important. J. Climate, 18, 2637-2646, https://doi.org/10.1175/ JCLI3431.1.

Razak, A. A., A. Hagishima, N. Ikegaya, and J. Tanimoto, 2013: Analysis of airflow over building arrays for assessment for urban environment. Build. Environ., 59, 56-65, https://doi.org/ 10.1016/j.buildenv.2012.08.007.

Runnalls, K. E., and T. R. Oke, 2006: A technique to detect microclimatic inhomogeneities in historical records of screenlevel air temperature. J. Climate, 19, 959-978, https://doi.org/ 10.1175/JCLI3663.1.

Shido, F., T. Aoyagi, N. Seino, F. Fujibe, and A. Yamamoto, 2015: Influence of nearby plants and artificial structures on the surface air temperature statistics: An in-situ measurement at central Tokyo(Otemachi) throughout years. Tenki, 62, 403-409.

Stull, R. B., 1988: An Introduction to Boundary Layer Meteorology. Kluwer Academic Publishers, 666 pp.
Sugawara, H., and J. Kondo, 1995: Sensitivity test of urban surface temperature. Tenki, 12, 813-818.

Sugita, M., 2018: Do windbreaks reduce the water consumption of a crop field? Agric. For. Meteor., 250-251, 330-342, https://doi.org/10.1016/j.agrformet.2017.11.033.

Vincent, L. A., X. L. Wang, E. J. Milewska, H. Wan, F. Yang, and V. Swail, 2012: A second generation of homogenized Canadian monthly surface air temperature for climate trend analysis. J. Geophys. Res., 117, D18110, https://doi.org/10.1029/ 2012JD017859.

Wada, N., T. Izumi, H. Matsuyama, and J. Kondo, 2016: The relationship between aspect ratio of windward open space and surface air temperature in the meteorological field derived from highly precise observation using fourfold radiation shielding funnel. Tenki, 63, 13-22.

Wang, H., and W. Klaassen, 1995: The surface layer above a landscape with a rectangular wind break pattern. Agric. For. Meteor., 72, 195-211, https://doi.org/10.1016/0168-1923(94) 02167-I.

Watanabe, T., and J. Kondo, 1990: The influence of canopy structure and density upon the mixing length within and above vegetation. J. Meteor. Soc. Japan, 68, 227-235, https://doi.org/ 10.2151/jmsj1965.68.2_227.

WMO, 2008: Guide to meteorological instruments and methods of observation. 7th ed., WMO 8, 716 pp., http://library.wmo.int/ pmb_ged/wmo_8_en-2012.pdf.

Yoshie, R., H. Tanaka, T. Shirasawa, and T. Kobayashi, 2008: Experimental study on air ventilation in a builtup area with closely-packed high-rise buildings. J. Environ. Eng. AIJ, 73, 661-667, https://doi.org/10.3130/ aije.73.661. 